\title{
Analysis of the effects of pulse shape and width on the retiming properties of a $3 R$ regenerator
}

Zibar, Darko; Oxenløwe, Leif Katsuo; Mørk, Jesper; Clausen, Anders; Jeppesen, Palle

Published in:

European Conference on Lasers and Electro-Optics, 2007 and the International Quantum Electronics Conference. CLEOE-IQEC 2007.

Link to article, DOI:

10.1109/CLEOE-IQEC.2007.4386432

Publication date:

2007

Document Version

Publisher's PDF, also known as Version of record

Link back to DTU Orbit

Citation (APA):

Zibar, D., Oxenløwe, L. K., Mørk, J., Clausen, A., \& Jeppesen, P. (2007). Analysis of the effects of pulse shape and width on the retiming properties of a 3R regenerator. In European Conference on Lasers and Electro-Optics, 2007 and the International Quantum Electronics Conference. CLEOE-IQEC 2007. (pp. 1-1). IEEE. https://doi.org/10.1109/CLEOE-IQEC.2007.4386432

\section{General rights}

Copyright and moral rights for the publications made accessible in the public portal are retained by the authors and/or other copyright owners and it is a condition of accessing publications that users recognise and abide by the legal requirements associated with these rights.

- Users may download and print one copy of any publication from the public portal for the purpose of private study or research.

- You may not further distribute the material or use it for any profit-making activity or commercial gain

- You may freely distribute the URL identifying the publication in the public portal 


\title{
Analysis of the effects of pulse shape and width on the retiming properties of a $3 R$ regenerator
}

\author{
D. Zibar, L. K. Oxenløwe, J. Mørk, A. T. Clausen and P. Jeppesen \\ COM•DTU, Technical University of Denmark, Ørsteds Plads 343, DK-2800 Kgs. Lyngby, Denmark
}

Introduction: As the single-channel bit rate will increase towards $160 \mathrm{~Gb} / \mathrm{s}$ in future photonic networks, the effects of timing jitter on transmission performance becomes severe [1]. It is therefore essential for $3 \mathrm{R}$ regenerators to be able to significantly reduce the jitter of the degraded incoming data signal and thereby perform retiming. Several methods for $3 R$ regeneration have been investigated, see [1]; however, little attention has been given to retiming. In this paper, based on a newly developed numerical model, we investigate the jitter (retiming) transfer function of the $3 \mathrm{R}$ regenerator in the presence of the recovered clock signal. The effects of data signal jitter and pulse shape, recovered clock signal jitter and FWHM of control signal pulses on the timing jitter of the retimed data signal is investigated.

Model set-up and numerical results: The model set-up of a 3R regenerator is shown Fig. 1.The incoming data signal is at $160 \mathrm{~Gb} / \mathrm{s}$ and the pulse FWHM is $2.8 \mathrm{ps}$. The CR is based on an optoelectronic PLL and provides a $10 \mathrm{GHz}$ clock signal which drives the control pulse source. For further information and requirements on CR, please see [2].
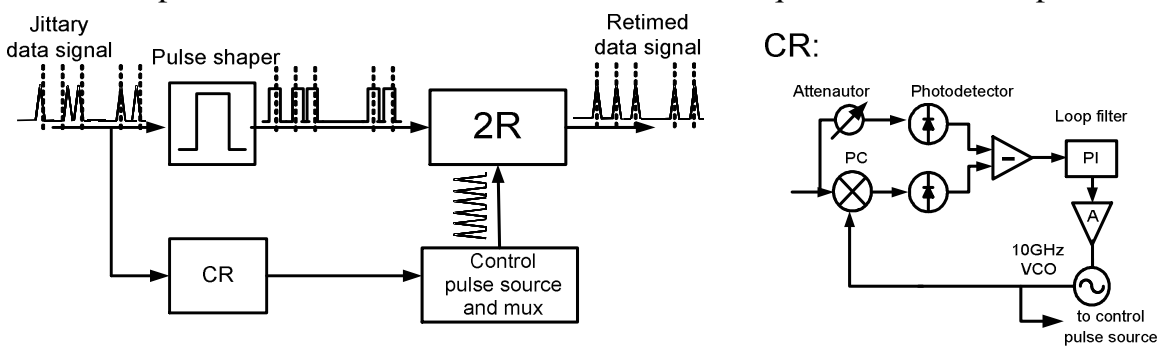

Fig. 1 Model set-up of an all-optical 3R regenerator. CR: clock recovery, PC: phase comparator, A: amp gain

The degraded incoming data signal is split at the input of the $3 \mathrm{R}$ regenerator and one part of the signal is sent to the CR and the other part of the signal is sent to the pulse shaper. The pulse shaper shapes the input data signal pulses into flattop pulses. Thereafter, the flat-top pulses are sent to the optical decision gate $(2 \mathrm{R})$ for the regeneration. We analytically model the whole system as an Ornstein-Uhlenbeck process and we end up with an analytical expression for the spectrum of the re-timed data signal. Jitter is modelled as Brownian motion phase error.
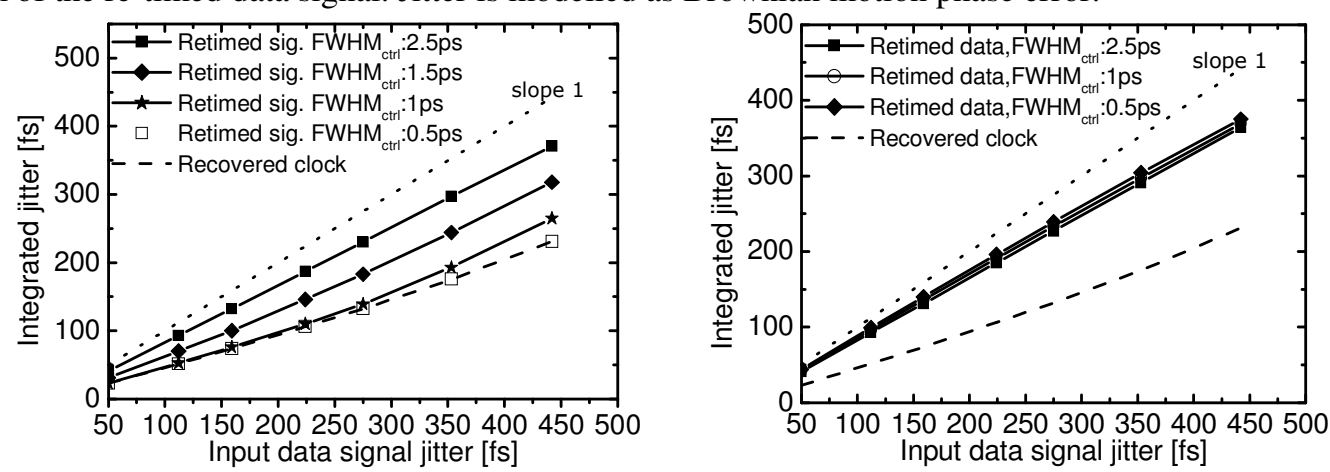

Fig. 2 Integrated jitter of the retimed data signal as a function of input signal jitter for different values of control signal FWHM. (a)

With pulse shaper. (b) Without pulse shaper. For reference, the recovered clock signal jitter is also plotted

In Fig. 2(a), the integrated jitter of the retimed data signal is computed as function of input signal jitter (jitter transfer function), for various values of the control signal FWHM (jitter Integration range: $2 \mathrm{kHz}-80 \mathrm{GHz}$.). The integrated jitter of the retimed data signal strongly depends on the FWHM of control signal pulses. As the control signal FWHM decreases, the integrated jitter of the retimed data signal approaches the jitter of the recovered clock signal. Only for very short control signal pulses $(0.5 \mathrm{ps})$, the retimed data signal jitter coincides with the recovered clock jitter. In Fig. 2(b), the pulse shaper is removed and the integrated jitter of the retimed data signal is computed as a function of the input data signal jitter. Fig. 2(b) shows that the jitter reduction can still be obtained; however, the reduction is very limited. Furthermore, the effect of the control signal pulse width is small and the performance improves as the FWHM is increased from $0.5 \mathrm{ps}$ to $2.5 \mathrm{ps}$ due to more flat top. However, it is not possible to match the jitter of the recovered clock signal and thereby obtain strong jitter reduction. In summary, we have shown that the jitter performance of a 3R regenerator significantly improves for flat-top data signal pulses and decreasing control signal pulse width.

References

1. S. Watanabe, J. Opt. Fiber, Commun. Rep3, 1-24, 2005

2. D. Zibar et al., CLEO' 06, Long Beach, California, U.S.A., Paper CMJ4, May 2006. 